\title{
LA ANDEREÑO DE IKASTOLA (1965-1985): UN NUEVO MODELO FEMENINO
}

\section{THE ANDEREÑO OF THE IKASTOLA (1965-1985): A NEW FEMALE MODEL}

\author{
Beatriz Gallego Muñoz \\ Centro de estudios: Instituto Universitario de Estudios de la Mujer (IUEM) \\ Universidad Autónoma de Madrid
}

\section{RESUMEN}

Las diversas experiencias educativas anteriores a la Guerra Civil supusieron el germen de futuras iniciativas basadas en la innovación pedagógica que culminarían con las ikastolas a partir de los años sesenta. Paralelamente se fue produciendo la evolución del perfil de sus docentes, las andereños, que contribuyeron decisivamente no sólo al desarrollo de este modelo educativo, sino a la normalización del euskera y al cambio social a través de la escuela. Las circunstancias en que desempeñaron su labor hacen de ellas un nuevo modelo femenino, que debe negociar las identidades basadas en los patrones tradicionales y las nuevas, que consigue logros pero también cae en sus propias contradicciones y que a pesar de su importancia no ha recibido el interés merecido.

Palabras clave: andereño, ikastola, trabajo femenino, imagen, género

\section{ABSTRACT}

The different educational changes undergone before the Spanish Civil War laid the grounds for future iniciatives based on teachign innovations that culminated in the ikastolas (Basque schools) from the 60's on. At the same time, the improvements in female teacher training not only contributed to the development of this new educational system, but also helped to establish the Basque Language and social changes through schools. The circumstances under which these women carried out work resulted in them becoming a new female model that had to negotiate the identities based on traditional and modern roles, that achieved milestones but also created their own contradictions and that despite its importance hasn't recieved the interest they deserve.

Keywords: Basque teacher, Basque school, women's work, image, gender 


\section{1.- Introducción}

A pesar de que el término «ikastola» se refiere a los centros donde la enseñanza de niños y niñas se realiza en euskera, su significado trasciende el ámbito puramente educativo y supone un modelo de participación de diferentes actores sociales (familias, profesorado, sectores de la Iglesia y de la cultura). Así, una de las características que define a esta institución escolar ha sido la de «la participación social en su nacimiento, gestión y desarrollo» (López-Goñi, 2008: 352). Además, está considerado un «movimiento popular» que, como tal, alberga prácticas y estrategias situadas «al margen de las acciones públicas y privadas, pero que tienen un importante protagonismo en la estructuración de la vida cotidiana» (Del Burgo, 2013: 73-88).

Puede decirse, por tanto, que el desarrollo de las ikastolas en el País Vasco y Navarra entre los años 60 y los 80 supuso una iniciativa decisiva para la conservación del euskera y la normalización de la enseñanza en ese idioma, aunque también una apuesta por una renovación pedagógica y un motor de innovación social. En este sentido, la mayoría de los estudios sobre estos centros se refieren a su aparición y desarrollo, en paralelo a los acontecimientos políticos y sociales de unas décadas cruciales en nuestra historia reciente. Pero debemos prestar más atención a la figura de las docentes (dada la feminización de esa profesión), denominadas andereños' ${ }^{\prime}$, como uno de sus principales agentes, ya que nadie cuestiona su labor pero parecen haber quedado en la sombra del propio momento histórico: el aspecto cooperativo de muchas ikastolas o su apuesta por una renovación pedagógica convierten a las profesoras en un colectivo importante pero al mismo tiempo anónimo, sin muchos referentes individuales conocidos $^{2}$.

Sin embargo, la importancia de estas docentes va más allá del ámbito laboral en el que desarrollaron su actividad y repercute en el conjunto de la sociedad. Pero para comprender tanto su influencia como la escasa atención que han recibido resulta fundamental analizar su figura desde el punto de vista del género, ya que representan las desigualdades y contradicciones del sistema educativo y social: la invisibilización personal frente al papel del colectivo, la perpetuación de prejuicios de género, las dinámicas económicas y sociales pero también la lucha por una renovación pedagógica o el ingenio frente a las dificultades económicas y sociopolíticas. La combinación de esos y de otros elementos les hará transgredir espacios físicos y simbólicos y hará de ellas un nuevo modelo de mujer.

\footnotetext{
1 «Andereño» significa tanto «señorita» como «maestra de escuela». El equivalente masculino de maestro sería «maisu», mientras que la traducción de «señorito» sería «jauntxo» (Diccionario Elhuyar).

2 Así, resulta curiosa la escasez de documentos encontrados en las bases de datos introduciendo como término de búsqueda el de «andereño» frente a otros como «ikastola» a pesar de que ambas nociones van necesariamente unidas.
} 106 


\section{2.-Mujer y educación en el ámbito vasco}

Los estudios referentes a las mujeres y la educación a nivel estatal se han centrado sobre todo en el análisis de las transformaciones producidas durante la Edad Contemporánea y especialmente a partir de la Ley Moyano de 1857, que declaró obligatoria la enseñanza tanto para niños como para niñas entre los seis y los nueve años. Esta medida generó la aparición de las Escuelas Normales de Maestras, profesionalizando al personal femenino docente que hasta entonces carecía de titulación y en muchas ocasiones incluso de capacitación (Cortada, 1999). Desde ese momento puede decirse que existe una enorme vinculación entre mujeres y docencia, convirtiéndose esta en una profesión predominantemente femenina, sobre todo en las etapas educativas más tempranas.

Tal y como señala Miren Llona, una de las razones que explican la feminización de la enseñanza es la existencia de una identificación entre esta y las tareas asociadas a la maternidad. Este hecho favoreció que, al igual que sucedía por ejemplo con las enfermeras (vinculadas también al ámbito de los cuidados y situadas en una posición subalterna respecto a los médicos varones), a principios del siglo XX ejercer como maestra se convirtiera en una aspiración respetable incluso para mujeres de clases medias (frecuentemente, venidas a menos) sin que eso supusiera una excesiva contradicción entre los prejuicios de clase y de género. Esta legitimación entre magisterio y feminidad motivó un fenómeno opuesto: mientras que las maestras fueron incorporándose a la esfera pública ${ }^{3}$ y posibilitaron la normalización de la asociación entre los términos «trabajo asalariado» y «feminidad de clase media» (Llona, 2002: 299-301), la profesión de maestro estaba desprestigiada y mal pagada (Rincón y Anzizar, 2014: 31). En el ámbito vasco, además, las denominadas Escuelas de Barriada surgidas en los años 20 a iniciativa de las Diputaciones y que desaparecieron con la guerra civil no sólo llevaron la educación a las zonas rurales, así como a los barrios mineros e industriales, sino que supusieron también una oportunidad laboral para mujeres con formación en magisterio y que hablaban euskera (Arrien, 1987: 83-85), especialmente porque si superaban el exigente proceso de selección accedían a un sueldo mucho más alto que el de las maestras de las escuelas nacionales (Rincón y Anzizar, 2014: 23).

Por otro lado, es importante señalar que al igual que el ejercicio del magisterio no suponía una contradicción con los prejuicios de clase y de género imperantes a comienzos del siglo XX, tampoco entraba en conflicto con otro elemento muy presente en la sociedad vasca e incluso en zonas de la navarra, como era el rol de la mujer en el nacionalismo. Así,

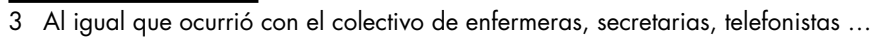


la base católica sobre la que se asienta la ideología de Sabino Arana sitúa a la mujer en un plano de inferioridad respecto al hombre y la limita al ámbito familiar, donde le otorga una gran responsabilidad en la transmisión de la cultura y el idioma (Acosta, 2013).

Este hecho será fundamental por varias razones: por un lado, porque de alguna manera en el imaginario popular y especialmente en aquel vinculado al mundo nacionalista se asume que la enseñanza del euskera y de lo que le rodea corresponde a las mujeres, es decir, no estaríamos hablando de conocimientos técnicos o científicos (vinculados a la razón) sino de un plano más vinculado a la emocionalidad; por otro lado, porque incluso dentro de las limitaciones que la doctrina sabiniana imponía a las mujeres, en el seno del Partido Nacionalista Vasco hubo figuras femeninas que destacaron en la esfera pública, por ejemplo como oradoras, y también existieron ámbitos exclusivamente femeninos, como Emakume Abertzale Batza (EAB). Esta institución, surgida con una vocación fundamentalmente de carácter asistencial, llegó a suponer una vía de evasión del mundo doméstico, una manera de relacionarse en sociedad e incluso de adquirir cierta formación y hasta una profesión. La vinculación de EAB con la enseñanza del/en euskera queda demostrada dentro y fuera del territorio vasco: por su relevancia en la creación de las Escuelas Vascas anteriores a la guerra civil (Rincón y Anzizar, 2014: 26-35) y en las experiencias postbélicas que finalmente culminarían con la creación de las ikastolas (Irazabal, 2008: 50) y por su compromiso con el idioma en la diáspora transmitiendo la lengua y la cultura vascas en las «euskal-etxeak» (Fernández, Uribe-Etxebarria, Zabaleta, Dávila y Larrazabal, 2008; Acosta, 2013).

Por último, cabe destacar que la manera en que se desarrolla la transmisión del idioma y la cultura en el ámbito doméstico (mediante la oralidad o las canciones, o dicho de otro modo, apoyándose en pocos medios materiales) será una constante en el movimiento de las ikastolas, especialmente en sus etapas de clandestinidad y alegalidad. Así, estos elementos (feminización del personal, compromiso con el proyecto motivado sobre todo por un sentimiento nacionalista, empleo de recursos mucho más intuitivos o vinculados a las emociones y sentimientos que técnicos), que caracterizarán al movimiento de las ikastolas cuando este comience su andadura no son especialmente cuestionados porque de alguna manera suponen una continuidad en la forma en que tradicionalmente se había realizado la educación.

Después de la guerra, el euskera es desterrado del ámbito público y queda relegado al espacio privado, a la esfera doméstica y familiar. Las experiencias educativas anteriores a la contienda quedan interrumpidas: se purgan los materiales y libros, parte de las personas que se dedicaban a la enseñanza y que habían sobrevivido son depura- 
das hasta el punto de que algunas de ellas nunca volverían a ejercer el magisterio y otras muchas partieron al exilio (Rincón y Anzizar, 2014: 36). Pero pese a las limitaciones existentes en el marco normativo franquista «entre 1939 y 1960 se mantuvo viva la llama de la euskaldunización que desembocó en la aparición de semillas de las ikastolas que hoy conocemos» gracias al mantenimiento y transmisión de la lengua en el ámbito doméstico. Esta tarea de conservación y legado de la herencia recibida, no exenta de un cariz de resistencia frente al poder, recayó fundamentalmente en las mujeres dados los roles de género de la ideología nacionalista y el desequilibrio demográfico entre sexos tras la contienda (Rincón y Anzizar, 2014: 74-75).

\section{3.- Perfiles y evolución de las andereños en paralelo a la sociedad}

Entre los años 40 y 60 las iniciativas para desarrollar una enseñanza en euskera van evolucionando en paralelo a algunos cambios producidos en la sociedad. En este sentido, resulta fundamental hablar de las «etxe-eskolak» o escuelas domésticas: casas particulares donde se enseñaba euskera de manera clandestina a grupos muy pequeños. La figura de Elvira Zipitria es clave en esta iniciativa: maestra nacionalista nacida en 1906, socia de EAB, tras el exilio (durante el cual siguió ejerciendo) regresó a San Sebastián en los años cuarenta y comenzó a dar clases en casa a niños y niñas procedentes de familias nacionalistas, aprovechando un pequeño vacío legal que permitía a maestras y maestros con titulación enseñar a menores hasta los nueve años; pronto, otras chicas comenzarían a formarse con ella para repetir esa iniciativa en otros domicilios, creando una especie de red de intercambio de conocimientos y experiencias (Irazabal, 2008: 52).

A pesar de que estas escuelas domésticas estuvieron muy limitadas al ámbito donostiarra, tuvieron una gran influencia en la creación de las ikastolas posteriores (Rincón y Anzizar, 2014: 81). El ingenio con que esas primeras andereños suplían la falta de medios (enseñando en el salón de una casa, usando el suelo ante la falta de pupitres, haciendo excursiones a menudo como forma de compensar recreos o juegos al aire libre de los que no disponían, pidiendo a sus alumnos y alumnas que llevaran cerillas con las que aprender a hacer los trazos de las letras para que no levantaran sospechas si les veían por la calle con cuadernos, etc. ${ }^{4}$ ) constituyen una muestra del espíritu de renovación pedagógica que más adelante preconizará el movimiento de las ikastolas.

4 «Andereños bajo el franquismo», El País, 20 de marzo de 2006. También la andereño Karmele Esnal relata experiencias similares para el proyecto Ahotsak (http://www.ahotsak.eus/orio/hizlariak/karmele-esnal-zulaika/). 


\section{4.- La renovación pedagógica de las ikastolas en el contexto de los cambios sociales del tardofranquismo}

A partir de finales de los años cincuenta y principios de los sesenta la sociedad experimentó importantes cambios económicos, sociales e ideológicos: era necesario modernizar la cultura y adaptarse a una sociedad eminentemente urbana, para lo cual resultaba fundamental impulsar campañas de alfabetización no sólo en euskera, sino en batua, es decir, en un euskera unificado (Dávila, Eizaguirre y Fernández, 1994: 96-97). Además, tras el nacimiento de ETA en 1959 comenzaron a surgir contradicciones en el seno del nacionalismo, en el que coexistían el viejo paradigma (que otorgaba una función muy importante a la religión y donde la figura de la mujer y/o la maestra se vinculaba a la maternidad) y otro más moderno, propio de una sociedad más laica en la que se percibía la llegada de otras corrientes ideológicas procedentes de Europa (socialismo, feminismo...) que influyeron en un nuevo modelo de género (Irazabal, 2008: 54).

Esa nueva sociedad que estaba comenzando a surgir demandaba otro tipo de sistema educativo: las escuelas domésticas, tan limitadas y cerradas, difícilmente podrían cumplir el objetivo de euskaldunizar a la población al que aspiraba el nacionalismo. Era necesario un sistema más abierto, más integrado en la calle y en el pueblo y vertebrado en torno a verdaderos centros escolares (Irazabal, 2008: 54) que superasen esas lecciones impartidas en grupos pequeños, en casas particulares y a escondidas: es el comienzo de las ikastolas, que surgieron con especial fuerza en Vizcaya y Guipúzcoa pero que se extendieron también a Álava y a Navarra. Durante años, funcionaron en un régimen de alegalidad hasta poder organizarse en las Federaciones de ikastolas y la Confederación de ikastolas que las aglutina ${ }^{5}$ y obtener el reconocimiento oficial, que no se producirá al mismo tiempo en todos los territorios (López-Goñi, 2005).

En paralelo a los cambios económicos y sociales que se produjeron en España durante los años sesenta, también se desarrollaron movimientos de renovación pedagógica que pretendían constituir alternativas al sistema educativo imperante en el franquismo, como las experiencias de Rosa Sensat o el movimiento Freinet. Este fenómeno renovador, que se asociaba a grupos de oposición al régimen y que fue especialmente significativo en Cataluña, también recogía corrientes educativas anteriores a la guerra civil y sirvió de modelo para las ikastolas gracias a la promoción de encuentros, intercambios, publicaciones, cursillos, etc. entre docentes en los años finales de la Dictadura (Rincón y Anzizar, 2014: 93-94).

En el caso de las ikastolas, las ideas de renovación pedagógica se plasmarán en el fomento de la expresión infantil en todas sus formas: verbal, gráfica, corporal, afectiva... (López- 
Goñi, 2005: 389); se parte de los intereses del propio alumnado, del concepto de su aprendizaje global, se flexibilizan los tiempos y los espacios y se establece un puente entre las Escuelas Vascas anteriores a la guerra y las ikastolas (López-Goñi, 2008: 357). Evidentemente existía un interés paralelo por recuperar la lengua vasca en un momento además en el que «se identifica euskera y libertad» y eso hace que grupos sociales contrarios a la dictadura se unan en la clandestinidad o en la semiclandestinidad «para trabajar a favor de las libertades y la recuperación lingüística y cultural» (López-Goñi, 2008: 352). Es decir, no sólo se trataba de la transmisión del euskera sino de la cultura vasca (Irazabal, 2008: 46) que, implícitamente, suponía un elemento transgresor ${ }^{6}$.

En ese contexto, las diferentes maneras de asociacionismo (bajo la forma de grupos de montaña, culturales, deportivos, asociaciones de padres...) constituyeron importantes espacios de encuentro de gente con ideas nacionalistas. Además, mediante acciones con un carácter principalmente simbólico (elaboración y reparto de panfletos, exhibición de ikurriñas o al menos de sus colores...) se daba una imagen de acción (Rincón y Anzizar, 2014: 48)7. Gracias a los cambios políticos y sociales que comenzaron a producirse en esa época se desarrolló en la década de los años 70 lo que Dávila, Eizaguirre y Fernández denominan la etapa de «alfabetización expansiva», es decir, "el paso de una sociedad de silencio a una sociedad donde la calle se toma como lugar de reivindicaciones populares», que influirá notablemente en el proceso de alfabetización y que precedería a la de «alfabetización institucional» de los años 1980-1990 (1994: 87-88).

\section{5.- Las ikastolas y las implicaciones de este nuevo modelo educativo}

En el modelo de enseñanza propugnado por las ikastolas la educación se aborda como algo holístico: madres, padres y otros agentes sociales pueden ejercer también como educadores (López-Goñi, 2005: 390) ${ }^{8}$. Especialmente en el caso de los progenitores, son muchos los ejemplos que aportan Aintzane Rincón y Arantza Anzizar para la ikastola de San Nikolas de Algorta y que demuestran el nivel de compromiso de quienes fundaron estos centros en sus barrios o pueblos: sosteniendo el proyecto mediante cuotas, buscando fuentes

\footnotetext{
6 Como señalan Aintzane Rincón y Arantza Anzizar, el movimiento de las ikastolas de los años sesenta se enmarca en un contexto de renacimiento cultural vasco que había comenzado a finales de los cincuenta y que quedó reflejado en la literatura, la música, el arte... (Rincón y Anzizar, 2014: 42).

7 También de grupos cuya ideología podía no ser nacionalistas pero sí de oposición al régimen.

8 Sobre las ikastolas, destacan los siguientes trabajos: Basurco, F. «La normalización de las ikastolas: breve historia y estado de la cuestión de la escuela pública vasca», en Historia de la Educación. Revista Interuniversitaria, n. ${ }^{\circ}$, 1989, págs. 139-165; Masa, M. Las Ikastolas como un fenómeno de innovación social: estudio de caso. Bilbao: Dpto. Sociología 2, Universidad del País Vasco (inédito), 2010; Arpal, J.; Asua, B. y Dávila, P. Educación y Sociedad en el País Vasco. Donostia-San Sebastián: Editorial Txertoa, 1982; -Onaindia, M. «La Escuela Pública Vasca y la construcción nacional», en Cuadernos de Alzate, n. ${ }^{\circ} 20,1994$, págs. 9-63; Fernández, I. Oroimenaren hitza. Ikastolen historia 1960-1975. Bilbao: Udako Euskal Unibertsitatea, 1994; Dávila Balsera, P. Enseñanza y educación en el País Vasco contemporáneo. Donostia -San Sebastián: Editorial, Erein, 2003.
} 
de financiación (desde montar puestos de venta en fiestas hasta solicitar apoyo económico a particulares e instituciones), colaborando en el acondicionamiento de locales, realizando acompañamientos en salidas, cediendo materiales y espacios, etc ${ }^{9}$.

La participación de madres y padres sobre todo en esos primeros años favorece la horizontalidad y convierte a las ikastolas en un proyecto pedagógico poco jerarquizado (López-Goñi, 2008: 359), muy distinto del ambiente que predominaba en la escuela tradicional franquista. Así, si esta se caracterizaba por la estricta disciplina o la separación de sexos, en las ikastolas la escolarización era mixta y la escasez de materiales e incluso de mobiliario adaptado a esas edades (especialmente en su época de clandestinidad) favorecía el uso del suelo, del círculo y la economía de medios mediante todo tipo de soluciones ingeniosas (Rincón y Anzizar, 2014: 61-92). Además, el uso de canciones, poesías, teatros y similares como instrumento pedagógico otorgaba un componente lúdico al proceso de aprendizaje.

Ese proyecto educativo moderno (aunque, como hemos visto, vinculado a experiencias pedagógicas anteriores a la Guerra Civil), novedoso, en un contexto de cambio económico y social, traspasa los muros del aula y se hace presente en la calle, como con la celebración de determinadas festividades. Tal y como señala Irene López-Goñi, hay «un optimismo pedagógico respecto a la función que puede ejercer la escuela como motor de cambio en la sociedad» y desde la ikastola se proyectan actividades que inciden en la vida cultural del barrio o del pueblo, que se ve llamado a la participación y dinamizado (2005: 390). Hay que considerar que además del perfil de maestras vascoparlantes estaba el de otras chicas que no tenían formación y que se instruyeron principalmente en la práctica: jóvenes, euskaldunes, motivadas, dispuestas a desplazarse para trabajar en otros sitios, a cobrar muy poco y sin cotizar a la Seguridad Social, a invertir horas de su tiempo libre en organizar actividades con el alumnado, a colaborar voluntariamente como profesoras de euskera para grupos de adultos... (López-Goñi, 2008: 363).

Es decir, la juventud, el dinamismo, el compromiso, la voluntariedad o la intuición (más que la experiencia o la formación específica) fueron elementos habituales en las andereños de esas primeras ikastolas. Y tal vez sea esa mezcla de elementos la que contribuye en gran medida a la normalización lingüística, hasta el punto de que paulatinamente las actividades organizadas por las ikastolas en la calle (desfiles en Nochebuena con motivo del Olentzero, canciones en Santa Águeda, actividades de carnaval, tamborradas, etc.) se han ido incorporando a la vida de los pueblos. 


\section{6.- Propuestas metodológicas para el estudio de las andereños}

Las mayoría de las investigaciones sobre el fenómeno de la enseñanza del euskera y las ikastolas se basan sobre todo en fuentes históricas relativas a la administración (por ejemplo, comunicaciones con el Ministerio de Educación en un principio y con el Departamento de Educación del Gobierno Vasco después, con las diputaciones y con ayuntamientos solicitando permisos de habilitación de edificios, de reconocimiento legal, de validación curricular, de celebración de fiestas) así como en la evolución del marco legal en que éstas se desarrollaban. Además, proporcionan valiosa información del funcionamiento de estos centros a nivel pedagógico (metodología, materiales, etc.) y en este sentido destacan el protagonismo de las andereños en la difusión de la educación en euskera (Elustondo, 2011) y su importancia como colectivo profesional cuando las ikastolas ya están en proceso de expansión.

Sin embargo, sólo en contadas ocasiones este estudio se ha abordado desde la perspectiva de género ${ }^{10}$ y este punto de vista es ineludible si se habla de una institución como la escolar, tradicionalmente feminizada, y especialmente si nos fijamos en la trayectoria del movimiento de las ikastolas y en el perfil de las docentes que lo hicieron posible.

Si se analiza la figura de la maestra euskaldun de posguerra, que tuvo que ejercer clandestinamente en las escuelas domésticas, y la de la andereño de ikastola de finales de los sesenta hasta los ochenta, puede observarse que se trata de dos generaciones muy diferenciadas aunque con elementos en común: la primera, nacida a principios del siglo XX y procedente de un contexto nacionalista, trabaja en «eskola-etxeak» urbanas, dando clases particulares a grupos reducidos en el propio domicilio, y tiene como máximo exponente a Elbira Zipitria, quien además realizó una importante labor en la formación de futuras docentes; la segunda generación, en cambio, estaría compuesta por chicas nacidas durante el franquismo y que en los años sesenta-setenta comienzan, muy jóvenes, a ejercer en ciudades pero también en pueblos en ocasiones alejados de su lugar de origen, en un contexto histórico que se prolongó hasta entrados los años ochenta y caracterizado por reivindicaciones políticas y sociales (últimos años de la dictadura, actividad de ETA, lucha obrera, aprobación de los Estatutos de Autonomía, legalización de la enseñanza en euskera...) en las que el idioma también tuvo una función destacada (Irazabal, 2008).

La primera generación ha originado considerable bibliografía sobre todo por su papel de pioneras de un proyecto educativo que aún hoy se mantiene e incluso crece. Pero esas andereños de la segunda generación parecen haber quedado eclipsadas por el mo-

10 Sí lo han hecho Eunate Irazabal Olarreta, asi como Aintzane Rincón y Arantza Anzizar (ver bibliografía). 
mento histórico en el que desarrollaron su actividad: el aspecto cooperativo de las ikastolas, el hecho de que favorecieran el rol activo de padres, madres y otros agentes sociales como educadores, etc. (López-Goñi, 2008) contribuye a que las docentes sean vistas y recordadas como colectivo (y dentro de un colectivo), y no tanto en su individualidad. De hecho, no parece que sus nombres hayan trascendido más allá de las ikastolas donde ejercieron.

Es cierto que la obra de ambas generaciones se ha estudiado desde el punto de vista de la labor que la mujer tradicionalmente ha desempeñado en la transmisión y difusión del euskera y la cultura vasca. En el caso de la segunda, además, se trata de una tarea que en las últimas décadas resulta aún más visible por su participación en iniciativas que sacan el idioma a la calle y lo vinculan también al ocio y la socialización en actividades como la Korrika (Del Valle, 1988), extendiéndolo así a la comunidad.

Pero si las ikastolas se han considerado, más allá de un modelo educativo, un «movimiento popular y paradigma de innovación social» (Del Burgo, 2013) debemos prestar más atención a la figura de las andereños como uno de sus principales agentes. Así, resultará interesante analizar el impacto causado por estas tanto entre el alumnado como entre la población de los barrios o los pueblos con la que se relacionaron, ya que en muchos sitios podían representar un nuevo prototipo de mujer: joven, independiente, llegada a áreas urbanas o rurales castellanoparlantes desde un entorno completamente euskaldun, algunas vinculadas a movimientos políticos, sociales o culturales (abertzalismo, feminismo, bertsolarismo...), en ocasiones también implicada en la euskaldunización de adultos a través de las escuelas nocturnas o «gau-eskolak», con iniciativas que pretenden llevar el idioma a la calle de una manera práctica y lúdica.

Por otra parte, estas andereños, sobre todo en núcleos pequeños, debían constituir un grupo quizás no numeroso pero sí diferenciado. En primer lugar, porque comprensiblemente tenderían a relacionarse entre sí por motivos de afinidad (de edad, profesión, procedencia, cultural...). Y, además, porque de manera natural y a falta de una coordinación orgánica se fueron agrupando con otras andereños de pueblos cercanos en forma de grupos de trabajo y apoyo, para crear materiales, etc. (López-Goñi, 2008: 362). Es decir, en torno a la enseñanza en las ikastolas se constituyen ciertas redes que no tendrían por qué ser endogámicas, sino que pudieron suponer un núcleo que permitiera aglutinar a individuos interesados por el euskera o por los elementos (culturales, ideológicos...) agrupados alrededor de este. Si se trataba de una zona con ciertos niveles de euskaldunización, puede que estas fueran vistas en su papel de «transmisoras» de la cultura. Pero en aquellos núcleos más claramente castellanoparlantes quizás su figura estuviera más cuestionada por determinados sectores desde el punto de vista ideológico, como representantes de una lengua o cultura sentida más como ajena que como propia.

114

Dossiers Feministes, 21, 2016, 105-119 - ISSN: $1139-1219$ - DOI: http://dx.doi.org/10.6035/Dossiers.2016.21.7 
Además, por su juventud y por el alto grado de compromiso con el proyecto educativo del que formaban parte hace pensar que en un contexto sociopolítico y cultural como es el de finales de los años sesenta hasta los ochenta también estuvieran vinculadas a otros movimientos sociales, culturales o políticos (feminismo, abertzalismo...) y que, quizás, esto se reflejara en su pedagogía. Estas circunstancias pudieron favorecer su integración en unos núcleos pero dificultarla en otros $y$, en este sentido, es posible que el factor género tuviese cierta influencia.

Si se pudiera recabar información sobre la función desempeñada por estas andereños en la enseñanza del euskera tanto en lo referente a la educación formal (ikastolas) como a la no-formal («gau-eskolak», iniciativas relacionadas con sacar el euskera a la calle...) podría analizarse su importancia no sólo como transmisoras de la lengua y la cultura vascas, sino también como referentes de un nuevo modelo de mujer, con sus diferencias (y similitudes) con aquellas de su entorno tradicional o de aquél en el que desarrollaron su actividad.

Para ello, se propone de manera prioritaria realizar entrevistas orales a andereños y personal de ikastolas que ejercieron su actividad en centros del País Vasco y Navarra entre los años 60 y 80 como forma de conocer sus experiencias de primera mano: contexto del que procedían, experiencia previa, condiciones laborales en las que ejercieron en las ikastolas, dificultades que encontraron y estrategias de adaptación, etc. Además, la realización de otro tipo de entrevistas aportarán los testimonios de personas que contribuyeron a la creación y mantenimiento de las ikastolas servirán para contrastar la información y diversificar las perspectivas bajo las que se puede analizar el papel de estas andereños: a padres y madres que impulsaron esa iniciativa (motivación, objetivos, dificultades que se encontraron, frustraciones, satisfacciones...) o a antiguo alumnado que asistió a la ikastola en ese periodo (percepción de lo que suponía la ikastola con respecto a la escuela, percepción del profesorado o de la organización de ambos modelos de centros, etc.), por ejemplo.

\section{7-Conclusión}

La función de las andereños ha sido tradicionalmente analizada siguiendo la evolución de las diferentes iniciativas educativas del ámbito vasco. Sin embargo, desde esta perspectiva encontramos la repetición de roles y estereotipos de género que las sitúan en una posición contradictoria: parecen ser elementos indispensables de la evolución educativa y social pero, inexplicablemente, se las coloca en un segundo plano respecto a las instituciones que ellas mismas construyen, impulsan y alimentan. Así, parece que su rol se limita al ámbito educativo, cuando en realidad su influencia fue sobre todo a nivel social, especialmente si 
nos centramos en la época del tardofranquismo, la transición y los primeros años de la democracia. Resulta además significativo que las precarias condiciones en que estas jóvenes ejercían suelan suavizarse bajo conceptos muy vinculados al trabajo femenino y especialmente al magisterio: maternalismo, búsqueda de nuevos horizontes, vocación, reconocimiento social más que económico, etc. Igualmente, destaca que esta visión sea compartida por antiguas andereños, como se desprende de testimonios recogidos en AHOA y en AHOTSAK. Y sin embargo, deberían analizarse con mayor profundidad las razones por las que estas mujeres (en mucha mayor medida que los hombres) desarrollaron su actividad en esas condiciones.

Como ya se ha mencionado, la función desempeñada por estas mujeres fue mucho más allá del ámbito educativo: si la enseñanza en euskera evoluciona y va ganando visibilidad y legitimidad a medida que consigue salir del interior de casas particulares a la plaza, del ámbito totalmente clandestino y privado de las escuelas domésticas hasta las ikastolas, podemos decir que algo similar sucede con sus andereños. Especialmente desde los años sesenta y setenta en que el status de las ikastolas se sitúa en un marco de alegalidad (aun así, muy diferente de aquel de clandestinidad propio de la época anterior), las andereños no sólo sacan el euskera a la calle: al hacerlo, ellas también salen, se visibilizan. Y al hacerlo, precisamente, en ese momento de cambio económico, social y político en el que se estaban renegociando identidades también a nivel de género, representan un nuevo modelo de mujer, especialmente cuando ejercen en zonas muy diferentes a sus localidades de origen. Así, más allá de su trabajo y especialmente en pueblos pequeños, las andereños transgreden de manera física y simbólica espacios tradicionalmente ocupados por gentes de esa localidad y sobre todo por los hombres de allí: la plaza como espacio de socialización y escaparate del euskera, la taberna como punto de encuentro con gente con inquietudes culturales y políticas similares o la escuela nocturna desde donde alfabetizaban en euskera a personas adultas, por ejemplo. Mediante lo que Amelia Valcárcel denomina los «infinitésimos morales», aquellas acciones espontáneas e individuales, en apariencia poco significativas, que se oponen a la norma que muchas mujeres «han hecho y hacen sin tener para nada la conciencia de ser feministas» (2008, p.331), estas mujeres con escasos recursos materiales consiguieron logros que las beneficiarían no sólo a ellas, sino a las generaciones futuras y contribuyeron decisivamente a sentar las bases de una sociedad potencialmente igualitaria. Con su trabajo en el aula pero también con su presencia y con su ejemplo fuera de ella, posibilitaron la enseñanza del euskera y su cultura, pero también que otras mujeres y otros hombres que mostraban interés o sensibilidad hacia estos ámbitos se acercaran a ese mundo y/o escolarizaran a sus hijas e hijos en las ikastolas. De esa forma se refuerza el papel de la escuela como motor del cambio social, pero sobre todo se humaniza el mismo concepto de escuela: más allá de la institución, se trata de personas.

116

Dossiers Feministes, 21, 2016, 105-119 - ISSN: 1139-1219 - DOI: http://dx.doi.org/10.6035/Dossiers.2016.21.7 
Es por ello que se plantea la necesidad de recabar testimonios de esas mujeres ly de quienes se relacionaron con ellas en ese contexto) que fueron fundamentales en ese cambio y que pueden reflejar su posición como bisagra: entre dos generaciones una nacionalista clásica y otra más de izquierdas; entre dos mundos, el euskaldun y el erdaldun; y entre dos momentos políticos, dictadura y democracia, con sus propias contradicciones y fortalezas. Sus testimonios, así como los de personas que las conocieron en su faceta académica (alumnado de ikastolas y de gau-eskolak) y fuera de ella (por convivencia, amistad, afinidad) podrían reflejar el impacto que sus ideas, su presencia, su metodología, su origen, etc. causaron en los lugares donde se crearon las primeras ikastolas. Así, más allá de su tarea educativa, estas jóvenes procedentes en la mayoría de los casos de entornos geográficos, sociolingüísticos, políticos y culturales muy diferentes de los que predominaban en los núcleos donde ejercieron pudieron convertirse en un modelo de mujer seguramente desconocido para una parte importante de la población, sobre todo en los casos de ikastolas rurales de zonas menos familiarizadas con el euskera.

Ese papel transgresor se sitúa en gran parte dentro del marco de las relaciones de género socialmente aceptadas al hacerse desde el área de los cuidados pero también deberá enfrentarse a las propias contradicciones. Por ejemplo, lo primero que se buscaba en ellas eran unas características muy asociadas a los roles femeninos, destacando las aptitudes maternales (la prioridad son los niños y niñas de corta edad) y la abnegación o sacrificio (los salarios eran muy bajos a pesar de que debían desplazarse lejos de sus hogares, encontraban dificultades para relacionarse con gente con un perfil similar, etc.) aunque mucho más allá de eso posibilitaron una ambiciosa renovación pedagógica. Sin embargo, ese trabajo no necesariamente se recompensará otorgándoles capacidad de decisión mediante el desempeño de cargos directivos, por ejemplo. Asimismo, una vez legalizadas las ikastolas, el perfil del personal docente dejará de estar tan feminizado y gozará de un reconocimiento mayor.

Además, el ámbito de influencia de estas andereños se encontraba no sólo dentro de las aulas, sino también fuera, de manera que su apariencia, actividades, actitudes, etc. podían ser tanto protestadas como admiradas por diferentes sectores. Así, muchas de ellas contribuyeron a la euskaldunización de la población infantil pero también a la de grupos de personas adultas mediante gau-eskolak. Sin embargo, al tratarse de educación no-formal, realizada en bastantes ocasiones de manera voluntaria, muy vinculada a visibilizar el euskera y la cultura vasca como parte de su normalización, etc. es muy posible que estos objetivos, así como los métodos para lograrlos, chocaran con estereotipos de género vigentes sobre lo que una mujer que además se dedicaba a la enseñanza infantil debía o podía hacer o no. Igualmente, es muy posible que debieran enfrentarse a otro tipo de prejuicios, más políticos, 
en un momento en que el euskera seguía asociado a la clandestinidad.

De ese modo, la figura de la andereño puede aparecer como un referente nuevo de mujer moderna en un momento de cambio social a todos los niveles, también de género, y en ese sentido conquistará espacios pero también se enfrentará a conflictos personales y a otros impuestos por las normas morales que se prestarán a una reflexión individual y también a una lectura en clave antropológica.

\section{Bibliografía}

Acosta, Ainhoa (2013): «El rol de las mujeres vascas en la transmisión del euskera: el idioma en las dinámicas de género e identidad», http://www.euskonews.com/0654zbk/ kosmo65401 es.html

ARRIEN, Gregorio (1987): Educación y escuelas de barriada de Bizkaia: escuela y autonomía, 1898-1936, Bilbao, Bizkaiko Foru Aldundia = Diputación Foral de Bizkaia.

BASURCO, Félix (1989): «La normalización de las ikastolas: breve historia y estado de la cuestión de la escuela pública vasca», Historia de la Educación. Revista Interuniversitaria, n. ${ }^{\circ}$, pp. 139-165.

CORTADA, Esther (1999): «De la «calcetera» a la maestra de escuela: expectativas y activismo profesional», Arenal, n 6: 1, pp. 31-53.

DÁVILA, Paulí (2003): Enseñanza y educación en el País Vasco contemporáneo, Donostia -San Sebastián, Erein.

Dávila, Paulí; Eizaguirre, Ana; Fernández, Idoia (1994): «Los procesos de alfabetización y escolarización en Euskal Herria (1860-1990), Cuadernos de Sección. Educación, 7, pp. 63-99.

Del Burgo, Unai (2013): «El movimiento cooperativo de las ikastolas: su revisión conceptual desde la perspectiva de las empresas sociales», Gezki, n. ${ }^{\circ}$ 10, pp. 71-96.

Del Valle, Teresa (1988): Rituales de la lengua en el espacio, Barcelona, Anthropos.

ElustONDO, Miel A (201 1): «Arabako euskara eta herrigintza joan deneko 25 urtean», Euskera, $\mathrm{n}^{\circ} 56$, vol. 3, pp. 577-588.

FERNÁNDEZ, Idoia (1994): Oroimenaren hitza. Ikastolen historia 1960-1975, Bilbao, Udako Euskal Unibertsitatea. 
Fernández, Idoia; Uribe-Etxebarria, Arantza; Zabaleta, Iñaki; Dávila, Paulí; Larrazabal, Lutxi (2008): «Euskal erbesteratzea, generoa eta hezkuntza: Euzkadi-Venezuela ikastola», Ikastaria, $n^{\circ} 16$, pp.369-392.

IRAZABAL, Eunate (2008): «Emakumea eta irakaskuntza», en Bat: Soziolinguistika aldizkaria, n 69 , pp. 45-59.

LÓPEZ-GoÑI, Irene (2005): «Las ikastolas en Navarra, (siglo XX): Búsqueda de un modelo de escuela propio», Historia de la Educación: Revista Interuniversitaria, ${ }^{\circ} 24$, pp. 371-396.

LóPEZ-GoÑI, Irene (2008): «La cuestión de la formación del profesorado de las ikastolas navarras de postguerra (1967-1983)», Ikastaria, n 16, pp. 351-367.

LLONA, Miren (2002): Entre señorita y garçonne. Historia oral de las mujeres bilbaínas de clase media (1919-1939), Málaga, Universidad de Málaga.

Rincón, Aintzane; AnzIZAR, Arantza (2014): Caminando por un sueño. Las primeraas andereños de la ikastola de San Nikolas (1963-1969), Getxo, Ayuntamiento de Getxo.

Valcárcel, Amelia (2008): Feminismo en el mundo global, Madrid: Cátedra/,universitat deValència/instituto de la Mujer.

\section{Páginas web:}

Aнол (Ahozko Historiaren Artxiboa/ Archivo de la Memoria): www.ahoaweb.org.

AHOTSAK (Archivo Oral Vasco): www.ahotsak.eus

AUÑAMENDI: http://www.euskomedia.org/aunamendi/153920/142533.

Recibido el 1 de marzo de 2016

Aceptado el 3 de abril de 2016 BIBLID [1 139-1219 (2016) 21: 105-119 